\title{
Finis Austriae. Prager Rückblicke auf die Habsburgermonarchie
}

Steffen Höhne, Finis Austriae. Retours pragois sur la monarchie des Habsbourg Steffen Höhne, Finis Austriae. Prague reviews of the Habsburg monarchy

\section{Steffen Höhne}

\section{(2) OpenEdition}

\section{Journals}

Édition électronique

URL : https://journals.openedition.org/austriaca/683

DOI : 10.4000/austriaca.683

ISSN : 2729-0603

\section{Éditeur}

Presses universitaires de Rouen et du Havre

\section{Édition imprimée}

Date de publication : 1 décembre 2019

Pagination : 35-62

ISBN : $979-10-240-1454-8$

ISSN : 0396-4590

\section{Référence électronique}

Steffen Höhne, „Finis Austriae. Prager Rückblicke auf die Habsburgermonarchie", Austriaca [Online], 88-89 | 2019, Online erschienen am: 31 Dezember 2020, abgerufen am 24 Oktober 2022. URL: http:// journals.openedition.org/austriaca/683 ; DOI: https://doi.org/10.4000/austriaca.683 
Steffen HöHNE

Musikhochschule Weimar

\section{Finis Austriae Prager Rückblicke auf die Habsburgermonarchie}

Das Jahr 1918 bedeutet für Zentraleuropa einen grundlegenden Einschnitt auf der politischen wie der lebensweltlichen Ebene. Wie reagiert die Literatur auf diesen Einschnitt? Am Beispiel deutschsprachiger Autoren aus Prag, Rilke und Kafka, Brod, Urzidil, Winder und Werfel werden sowohl die Auseinandersetzungen mit dem Jahr 1918 aus jeweils unterschiedlichen Perspektiven und Erfahrungen (nach 1918, nach 1933, nach 1945) als auch die über 1918 hinauswirkenden habsburgischen Prägungen untersucht.

\section{Der Zerfall Österreichs}

Friedrich Heer hatte konstatiert, es gäbe „kein geschichtliches Gebilde in Europa, dessen Existenz so sehr mit den Identitätsproblemen seiner Mitglieder verbunden " war wie Österreich ${ }^{1}$. Tatsächlich trugen identitätspolitische Konflikte um Fragen kollektiver Emanzipation maßgeblich zum Untergang der Habsburgermonarchie bei, auch wenn aufgrund eines weitverbreiteten Nebeneinanders nationaler, dynastischer und staatlicher Loyalitäten kein unmittelbarer und ursächlich kausaler Zusammenhang von Identitätspolitik und Ende der Monarchie behauptet werden kann. Zumindest bestand bis zum Ausbruch des 1. Weltkriegs eine Reform der Monarchie durchaus als Möglichkeit, wofür der Ausgleich in Mähren (1905) und der Bukowina (1910) sowie der nicht mehr umgesetzte in Galizien (1914) als Beispiel dienen mögen². Und es

1. Friedrich Heer, Der Kampf um die österreichische Identität (3. Aufl.), Wien, Köln, Weimar, Böhlau, 2001, S. 9.

2. Peter Urbanitsch, „Die nationalen Ausgleichsversuche in den Ländern Cisleithaniens in den Jahren vor dem Ersten Weltkrieg - Gemeinsamkeiten und Unterschiede“, in Lukaš Fasora, Jiří Hanuš und Jiří Malíŕ (Hg.), Moravské vyrovnání z roku 1905: možnosti a limity 
lassen sich weitere Argumente für den Bestand der Monarchie - zumindest in Friedenszeiten - finden:

- Das als vorbildhaft betrachtete dynastische Prinzip und die damit verbundene Solidarität der „blauen Internationale ${ }^{3 “}$ bzw. der Glaube an die Reformfähigkeit der Monarchie als ein konsensuelles Modell der politischen Eliten ${ }^{4}$.

- Die Monarchie, die weder bei regionalen noch bei globalen Ambitionen der übrigen Großmächte eine ernsthafte Konkurrenz bildete.

- Schließlich die stabilisierende Rolle der Monarchie als Puffer zwischen dem Deutschen Reich und Russland, ein Gedanke, den bereits Palacký in seinem Brief 1848 an die Frankfurter Paulskirche formuliert hatte ${ }^{5}$.

Tatsächlich lassen sich imperiale Prägungskräfte, die auf den Erfahrungsraum und den Erwartungshorizont einwirkten, bis in den Ersten Weltkrieg hinein feststellen, so dass der Topos der imperialen Heimat im Kontext eines multiethnischen Referenz- und Kommunikationsraums nicht nur auf der diskursiven, sondern auch auf der lebensweltlichen Ebene Relevanz beanspruchen darf ${ }^{6}$. Es ist erst der Weltkrieg, der eine Welt scheinbarer Selbstverständlichkeiten und Sicherheiten zerstörte und in dem, ungeachtet von Wahrnehmungen der Habsburgermonarchie als Verbindung bzw. Brücke zwischen West- und Osteuropa, als ein Europa im Kleinen ${ }^{7}$ oder als „Paradigma

národnostního smíru ve střední Evropě [Der Mährische Ausgleich von 1905: Möglichkeiten und Grenzen für einen nationalen Ausgleich in Mitteleuropa], Brno, Matice moravská, 2006, S. 43-58.

3. Otto Urban, Die tschechische Gesellschaft 1848-1918 (Bd. 1), Wien, Köln, Weimar, Böhlau, 1994, S. 826.

4. Tim Buchen, Malte Rolf, „Eliten und ihre imperialen Biographien. Zur Einführung“, in Dies. (Hg.), Eliten im Vielvölkerreich. Imperiale Biographien in Russland und ÖsterreichUngarn (1850-1918), Berlin, Boston, de Gruyter/Oldenbourg, 2015, S. 3-31, hier S. 25 f.

5. Urban, Die tschechische Gesellschaft, S. 826.

6. Moritz Csáky, „Paradigma Zentraleuropa: Pluralitäten, Religionen und kulturelle Codes. Religion, Mythos, Nation. Einführende Überlegungen“ in Ders., Klaus Zeyringer (Hg.), Pluralitäten, Religionen und kulturelle Codes, Innsbruck, StudienVerlag, 2001, S. 9-17. S.a. Peter Stachel, „Übernationales Gesamtstaatsbewusstsein in der Habsburgermonarchie. Zwei Fallbeispiele“, in Endre Kiss, Justin Stagl (Hg.), Nation und Nationenbildung in Österreich-Ungarn 1848-1938. Prinzipien und Methoden, Wien, LIT Verlag, 2006, S. 97-113. Zu der damit verbundenen Neudeutung der Habsburgermonarchie s. zuletzt Pieter Judson, Habsburg. Geschichte eines Imperiums 1740-1918, München, Beck, 2017, sowie die einschlägigen Artikel bei Johannes Feichtinger, Heidemarie Uhl (Hg.), Habsburg neu denken. Vielfalt und Ambivalenz in Zentraleuropa. 30 kulturwissenschaftliche Stichworte, Wien, Köln, Weimar, Böhlau, 2016.

7. Hans-Christian Maner, „Zentrum und Grenzregionen in der Habsburgermonarchie im 
für die gesamteuropäische Entwicklung8" diese einer zunehmenden Delegitimierung von innen, aber auch von außen unterlag, galt sie doch als das „geographisch am wenigsten organische und darum wohl am ehesten dem Zerfall ausgesetzte Staatengebilde Europas ${ }^{9 “}$. In der Diktion von Musils Kakanien-Metapher war es die Differenz zwischen Staat und Volk, zwischen Vaterland und Nation, die an den Topos der Überlebtheit der Monarchie gekoppelt waren. Ursache des Zerfalls ist die rückblickend erinnerte, auf territorialer Vielfalt basierende sprachliche, konfessionelle und ethnische Heterogenität. Bei Musil handelt es sich allerdings nicht nur um eine autobiographische Stilisierung, sondern man findet auch Reflexe auf charakteristische Fremdheits- wie Entfremdungserfahrungen:

So oft man in der Ferne an dieses Land dachte, schwebt vor den Augen der Erinnerung an die weißen, breiten, wohlhabenden Straßen aus der Zeit der Fußmärsche und Extraposten, die es nach allen Richtungen wie Flüsse der Ordnung, wie Bänder aus hellem Soldatenzwillich durchzogen und die Länder mit dem papierweißen Arm der Verwaltung umschlangen. Und was für Länder! Gletscher und Meer, Karst und böhmische Kornfelder gab es dort, Nächte an der Adria, zirpend von Grillenunruhe, und slowakische Dörfer, wo der Rauch aus den Kaminen wie aus aufgestülpten Nasenlöchern stieg und das Dorf zwischen kleinen Hügeln kauerte, als hätte die Erde ein wenig die Lippen geöffnet, um ihr Kind dazwischen zu wärmen ${ }^{10}$.

Ungeachtet nostalgischer Rückblicke setzten sich, was die politische Organisation des Staates anbetraf, die desintegrativ wirkenden Tendenzen durch. Die Vorstellungen vom Völkerkerker, so Musil, hatten erheblichen Anteil an diesem desintegrativen Prozess:

Es war schon beim Beginn der Parallelaktion einer seiner Gedanken gewesen, gerade jenen Teil der Kakanier deutschen Stammes für sie zu gewinnen, der sich weniger dem Vaterlande als der deutschen Nation zugetan fühlte. Mochten die anderen „Stämme“ Kakanien, wie es geschah, als ein Gefängnis bezeichnen und ihre Liebe für Frankreich, Italien und Rußland noch so öffentlich ausdrücken, so waren das doch sozusagen entlegenere Schwärmereien, und kein

18. und 19. Jahrhundert. Eine Einführung“, in Ders. (Hg.), Grenzregionen in der Habsburgermonarchie im 18. und 19. Jahrhundert. Ihre Bedeutung und Funktion aus der Perspektive Wiens, Münster, Lit, 2005, S. 9-24.

8. Egon Schwarz, „Schmelztiegel oder Hexenkessel? Juden und Antisemitismus im Wien der Jahrhundertwende“, in Ders., Wien und die Juden. Essays zum Fin de siècle, München, Beck, 2014, S. 7-32, hier S. 8.

9. Alfred Hettner, Europa (= Grundzüge der Landeskunde, 1), Leipzig, Spamer, 1907, S. 68.

10. Robert Musil, Der Mann ohne Eigenschaften, Berlin, 1975 [1931], S. 39. 
ernster Politiker durfte sie auf eine Stufe stellen mit der Begeisterung gewisser Deutscher für das Deutsche Reich, das Kakanien geographisch umklammerte und ihm bis vor einem Menschenalter einheitlich verbunden gewesen war $^{11}$.

Das weithin verbreitete Narrativ vom historischen Niedergang der Monarchie, jener so Robert Musil' ${ }^{12}$ „zweitschwächsten der Großmächte“, ist dabei nicht nur ein literarischer Topos, sondern korreliert mit Erwartungen vom „Zerfall Österreichs“, der schon 1870 bei Daniel Spitzer ${ }^{13}$ erscheint und in der Folge immer wieder im politischen Diskurs artikuliert wurde. Österreich habe keine Persönlichkeit entwikkelt $^{14}$, die gesellschaftliche Integration stand permanent in Frage, der kakanische „Staat als Lebensform“ konnte keine Zukunft haben ${ }^{15}$. Die fehlende Zukunftsperspektive der Doppelmonarchie müsste zwangsläufig zu einer Unterordnung bzw. Integration in ein neues Großdeutschland ${ }^{16}$ bzw. ein Deutsch dominiertes Mitteleuropa führen ${ }^{17}$, wobei insbesondere das Mitteleuropakonzept eine Lösung des geopolitischen „Problems“ Österreich-Ungarns zu bieten schien ${ }^{18}$. Untergegangen war 1918 - so der weit verbreitete Anachronismus-Topos - immerhin ein dynastischer Staat uralter Prägung, ein erratischer Block in einer bereits nach ganz anderen Gesetzen sich entwickelnden Welt, Überbleibsel einer feudalen Vergangenheit, mit einer teils verknöcherten, teils undurchschaubaren Gesetzgebung, einer von vielen für irrational gehaltenen Organisation $^{19}$.

11. Musil, Der Mann ohne Eigenschaften, S. $658 f$.

12. Musil, ebd., S. 40.

13. Daniel Spitzer, „Der Zerfall Österreichs, Graf Beust und andere Kleinigkeiten (18.9.1870)“, in Max Kalbeck und Otto Erich Deutsch (Hg.), Gesammelte Schriften, München, Leipzig, 1912, S. 354-356. S. Kurt Krolop, Ludwig Winder. Sein Leben und sein erzählerisches Frühwerk. Ein Beitrag zur Geschichte der Prager deutschen Literatur, Olomouc, Palacký-Universität, 2015, S. 31.

14. Rudolf Kjellén, Die Großmächte der Gegenwart, Leipzig, Berlin, 1917 [1915], S. 12.

15. Rudolf Kjellén, Der Staat als Lebensform, Leipzig, 1917. „Kein Staat ist frei von inneren Gegensätzen [...]. Eine Großmacht kann auch ohne Schwierigkeiten ein Irland ertragen, wie England, ja sogar drei wie Deutschland (Polen, Elsaß, Schleswig). Anders verhält sich die Sache aber, wenn die Großmacht 'nur aus Irlanden' besteht. Das ist bei ÖsterreichUngarn der Fall." (Kjellén, Großmächte der Gegenwart, S. 21).

16. Rudolf Kjellén, Die Großmächte der Gegenwart.

17. Friedrich Naumann, Mitteleuropa, Berlin, Georg Reimer, 1915.

18. Steffen Höhne, „Imperiale Ambitionen und das Recht der kleinen Nationen. 'Mitteleuropa' bei Naumann und Masaryk", in Jacques Lajarrige, Walter Schmitz, Giusi Zanasi (Hg.), „Mitteleuropa“. Geschichte eines transnationalen Diskurses im 20. Jahrhundert, Dresden, Thelem, 2011, S. 143-168.

19. Egon Schwarz, „Schmelztiegel oder Hexenkessel? Juden und Antisemitismus im Wien 
Dabei bedeutete das Ende der Habsburgermonarchie 1918 - jenes „slavisch-romanischen Mischlingsstaats an der Donau ${ }^{20 “}$ - ähnlich wie das Ende des Heiligen Römischen Reiches Deutscher Nation etwas über 100 Jahre zuvor einen politischen, ökonomischen, sozialen und kulturellen Einschnitt von epochaler Bedeutung für ganz Europa. Das Jahr 1918 wurde somit auch für die Böhmischen Länder zum Schicksalsjahr in zumindest zweifacher Hinsicht. Auf der einen, der tschechischen Seite schienen die jahrzehntelangen Bestrebungen auf nationale Emanzipation in einem eigenen Nationalstaat endlich in Erfüllung gegangen zu sein, auf der anderen, der deutschböhmischen und -mährischen, stand die Erfahrung politischer, sozialer und kultureller Minorisierung und Marginalisierung durch den Verlust der zuvor eingenommenen oder zumindest beanspruchten hegemonialen Position. Das eigene Territorium verwandelte sich in Peripherie, der versunkene Vielvölkerstaat avancierte bei nicht wenigen deutschsprachigen Autoren zu einem topographischen Sehnsuchtsort.

\section{Ambivalente Rückblicke aus Prager Sicht}

Bereits vor dem Krieg findet man in Prag distanzierte Positionen gegenüber der Monarchie, was sich an Äußerungen um den Charakter des Österreichischen zeigen lässt. Nach Rilke liege das Problem der Zeit darin, dass Österreich es nicht zu „einer ihm eigenen Sprache“ und deshalb auch nicht zu einer „eigentlichen Durchdringung seiner Bestandteile“ gebracht habe:

Die unselige Berührung von Sprachkörpern, die sich gegenseitig unbekömmlich sind, hat ja in unseren Ländern dieses fortwährende Schlechtwerden der Sprachränder zur Folge, aus dem sich weiter herausstellt, daß, wer etwa in Prag aufgewachsen ist, von früh auf mit so verdorbenen Sprachabfällen unterhalten wurde, daß er später für alles Zeitigste und Zärtlichste, was ihm ist beigebracht worden, eine Abneigung, ja eine Art Scham zu entwickeln sich nicht verwehren kann (Brief am 11.1.1914 an August Sauer) ${ }^{21}$.

Mit soziolinguistischer Argumentation liefert Rilke eine Erklärung für die offenkundige, auch sprachliche Desintegration in der Habsburgermonarchie, womit die nationalsprachliche, monolingualen

der Jahrhundertwende“, in Ders., Wien und die Juden, S. 7-32, hier S. 8.

20. Heinrich von Srbik, Deutsche Einheit. Idee und Wirklichkeit vom Heiligen Reich bis Königgrätz, München, F. Bruckmann, 1936, S. 59.

21. Rainer Maria Rilke, Briefe. Zweiter Band, hrsg. vom Rilke-Archiv in Weimar, Frankfurt/ Main, Insel, 1987, S. 434. 
bzw. monoglossischen Idealen verpflichtete Entwicklung als Ursache benannt wird ${ }^{22}$. Das „mehrsprachige“ Österreich, so vermerkt Rilke im April 1912, sei „nicht im reinen mit sich selbst.“

Hinzu komme eine (sprach)-politische Unzulänglichkeit der habsburgischen Administration. Das Österreichische, so Rilke an Ilse Erdmann (11.9.1915), sei „durch die Zeiten ein oberflächlicher Kompromiß geblieben [...]“ Genannt wird „die Unaufrichtigkeit als Staat“, weshalb ,im Oesterreichischen ein Zu-hause zu haben [...] rein undenkbar und unausführbar" $\operatorname{sei}^{23}$. Diese distanzierten Einstellungen Rilkes verstärken sich in der österreichischen Militärschule, aber auch durch die nationalen Konflikte in Prag, deren desintegrative Wirkung der junge Rilke erkannte ${ }^{24}$. „Es ist kaum zu sagen, wie sehr mir alles Österreichische zuwider ist," vermerkt Rilke am 10. Januar 1912 aus Duino an Lou Andreas-Salomé. Das Ideal einer österreichischen Staatsidee blieb für Rilke problematisch, Österreich „durch die Zeiten ein oberflächlicher Kompromiß“25. Rilke sprach gar von dem „Komposite meines Österreichertums" (Brief an Katharina Kippenberg am 19. April 192126). In einer Phase wachsender Abgrenzung von Deutschland zeigen sich bei Rilke - allerdings vermittelt über Stifter Apologien des Österreichischen. So werden der Nachsommer als „ein ,österreichisches Arkadien“", der Witiko als eine „slawisch-deutsche Geschichtsutopie"wahrgenommen ${ }^{27}$.

22. Zur sprachlichen Situation in der Habsburgermonarchie s. Hans Goebl, „Geschichte lernen und aus Geschichte lernen: Die altösterreichische Sprachenvielfalt und -politik als Modellfall für ein Europa von heute und morgen" in Ute Helferich, Claudia Maria Riehl (Hg.), Mehrsprachigkeit in Europa - Hindernis oder Chance? Wilhelmsfeld, Gottfried Egert, 1994, S. 55-82.

23. Rainer Maria Rilke, Briefe zur Politik, Frankfurt, hrsg. von Joachim W. Storck, Leipzig, Insel, 1992, S. 139.

24. Joachim W. Storck, „Rilke, Stifter und die ,Idee Österreichs“, in Rainer Maria Rilke und Österreich, Linz, Veranstaltungsgesellschaft, 1986, S. 75-85. Rilke, der im Brief an Marianne Mitford (5.3.1915) fragt, was man tun müsse, „um aus der Umklammerung einer sich enger schließenden [...] würgenden Nationalität hinauszukommen“ (Rilke, Briefe zur Politik, S. 106). Eine Lösung bieten dann die auf Ausgleich orientierten Zwei Erzählungen.

25. Brief an Ilse Erdmann (11.9.1915). Rilke, der „nicht ,deutsch empfinde“, obgleich „dem deutschen Wesen nicht fremd [...] da ich in seiner Sprache bis an die Wurzeln ausgebreitet bin", berichtet in einer Klage über die Zeitläufte von Befremdung gegenüber der deutschen Kultur, und von einer grundsätzlichen Heimatlosigkeit (Rilke, Briefe zur Politik, S. 139).

26. Rilke, Briefe zur Politik, S. 340.

27. Storck, „Rilke, Stifter und die ,Idee‘ Österreichs“, S. 84. 
Wie bei Rilke lässt sich auch für Kafka, der sich außerstande sah, „mir ein im Geiste einheitliches Österreichertum klar zu machen und noch weniger allerdings mich einem solchen Geistigen ganz eingefügt zu denken“" (an Fritz Lampl, 8. März 1917), keine austriazistische Orientierung unterstellen ${ }^{28}$. Das soll natürlich nicht heißen, es gäbe keinen Bezug zwischen Person und Kontext, zumal Kafka sehr wohl Kongruenzen zwischen „innerer Situation“ und dem Zustand des Staates evozierte. An Max Brod schreibt Kafka am 13. Januar 1921 aus Matliary/ Matlarenau:

Sie [Kafkas innere Situation, S.H.] erinnert ein wenig an das alte Österreich. Es ging ja manchmal ganz gut, man lag am Abend auf dem Kanapee im schön geheizten Zimmer, das Thermometer im Mund, den Milchtopf neben sich und genoß irgendeinen Frieden, aber es war nur irgendeiner, der eigene war es nicht. Eine Kleinigkeit nur, ich weiß nicht, die Frage des Trautenauer Kreisgerichtes war nötig und der Thron in Wien fing zu schwanken an, ein Zahntechniker, das ist er nämlich, studiert halblaut auf dem oberen Balkon und das ganze Reich, aber wirklich das ganze, brennt mit einemmal ${ }^{29}$.

Und die zentralen Krisen, Badeni-Unruhen 1897 in Prag, HilsnerAffäre $1899^{30}$ (mit der ein scheinbar überwundener, anachronistischer

28. Steffen Höhne, „Kafka und Prag. Kulturelle und mentale Prägungen als Wirkungsbedingungen", in Ders., Ludger Udolph (Hg.), Franz Kafka. Wirkung und Wirkungsverhinderung (= Intellektuelles Prag im 19. und 20. Jahrhundert, 6), Köln, Weimar, Wien, Böhlau, 2014, S. 259-280.

29. Franz Kafka, Max Brod (Hg.), Briefe 1902-1924, Frankfurt/Main, Fischer, 1975, S. $288 f$. 1891 wurde ein Kreisgericht in Trautenau mit Deutsch als Amtssprache geschaffen, was zu Unruhen unter den Prager Tschechen führte. - Bei dem Zahntechniker handelt es sich laut Auskunft von Hans-Gerd Koch, der derzeit den fünften Band der Briefe Kafkas vorbereitet, um Adalbert (Bela/Vojtěch) Glauber, eigentlich ein Zahnarzt, von Kafka aber als Zahntechniker erinnert, der am 26. Juli 1923 in Matlarenau an Lungentuberkulose starb.

30. Zu Analogien zwischen der desintegrativen Entwicklung, die am Vorabend des Ersten Weltkriegs auf dem österreichischen "Staatsschiff" herrschte und dem Verschollenen s. Boris Blahak, „Der Schreiber als Seismograph einer Zeitenwende. Reflexe einer mitteleuropäischen Endzeitstimmung in Franz Kafkas Romanfragment, Der Verschollene “", in Peter Becher, Steffen Höhne, Marek Nekula (Hg.), Kafka und Prag. Literatur-, kultur-, sozial und sprachhistorische Kontexte, Köln, Weimar, Wien, Böhlau (= Intellektuelles Prag im 19. und 20. Jahrhundert, Bd. 3), 2012, S. 231-252. Zum Antisemitismus in der KafkaZeit s. Christoph Stölzl, Kafkas böses Böhmen. Zur Sozialgeschichte eines Prager Juden, Frankfurt/Main, Berlin, Ullstein, 1989; Michal Frankl, „Prag ist nunmehr antisemitisch“. Tschechischer Antisemitismus am Ende des 19. Jahrhunderts, Berlin, Metropol, 2011 sowie Ines Koeltzsch, Geteilte Kulturen. Eine Geschichte der tschechisch-jüdisch-deutschen Beziehungen in Prag (1918-1938), München, Oldenbourg, 2012, speziell zu Hilsner: Benno Wagner, „Kafkas Polná. Schreiben jenseits der Nation“, in Marek Nekula, Walter Koschmal (Hg.), Juden zwischen Deutschen und Tschechen. Sprachliche und kulturelle 
Antisemitismus eine Aktualisierung und Radikalisierung erfuhr, die jegliche Assimilationsperspektive in Frage stellen musste), nach der Jahrhundertwende die bosnische Annexionskrise 1908, die Balkankriege 1912/13 und der 1. Weltkrieg, finden durchaus Niederschlag im Werk $^{31}$, in dem individuelle, aber auch staatliche Erosions- und Niedergangsphänomene immer wieder im Zentrum stehen. Die Erzählung Eine kaiserliche Botschaft, erschienen in der Selbstwehr am 24. September 1919, vermittelt ein Bild von auf die politische Realität leicht übertragbarer Unbeweglichkeit und Überlebtheit einer alten Monarchie mit dem öffentlich zelebrierten Ableben des Herrschers, „vor der ganzen Zuschauerschaft seines Todes ${ }^{32 “ . ~ D i e ~ E r z a ̈ h l u n g ~ E i n ~ a l t e s ~ B l a t t, ~ e r s c h i e-~}$ nen in Marsyas im September 1917, lässt sich wie in Roths Radetzkymarsch als Verfallsgeschichte eines Reiches mit einem isoliert lebenden Kaiser lesen. Kafka evoziert ein Bild von gesellschaftspolitischer Stagnation und Versäumnissen im Innern: „Es ist viel vernachlässigt worden in der Verteidigung unseres Vaterlandes. Wir haben uns bisher nicht darum gekümmert und sind unserer Arbeit nachgegangen; die Ereignisse der letzten Zeit machen uns aber Sorgen ${ }^{33}$. “

Vor und während der Kriegszeiten wird somit die Fragilität der habsburgischen Ordnung wahrgenommen. Wie haben die Akteure des Prager Kreises auf den Bruch 1918 reagiert?

\section{Konstruktive Neubestimmung: Habsburg-Traditionen im Prager Kreis}

\section{Max Brod}

Die von Jean-François Lyotard konstatierte „Trauerarbeit“ der Wiener Intellektuellen setzte schon um die Jahrhundertwende ein, wobei der mit 1918 verbundene Orientierungsverlust vor allem auf der

Identitäten in Böhmen 1800-1945 (Veröffentlichungen des Collegium Carolinum, 104), München, Oldenbourg, 2006, S. 151-172.

31. Steffen Höhne, „Nachdenken über kulturelle Zugehörigkeit. Neobohemistische Traditionen und nationale Desintegration in der Kafka-Zeit", in Peter Becher, Ders., Marek Nekula (Hg.), Kafka und Prag. S. 35-58; Manfred Engel, Ritchie Robertson (Hg.), Kafka, Prag und der Erste Weltkrieg. Kafka, Prague and the First World War (= Oxford Kafka Studies, 2), Würzburg, Königshausen \& Neumann, 2012.

32. Franz Kafka, Drucke zu Lebzeiten. Kritische Ausgabe, hrsg. von Wolf Kittler, Hans-Gerd Koch, Gerhard Neumann (Schriften, Tagebücher, Briefe), Frankfurt/Main, Fischer, 1994, S. 281.

33. Kafka, Drucke zu Lebzeiten, S. 263. 
lebensweltlichen Ebene als Einschnitt wahrgenommen wurde, als ein Abschied von Österreich, so Ludwig Winders Nachruf in der Bohemia am 17. Oktober 1918, durch den erst bewusst werde, „was uns Österreich gewesen ist“ bzw. durch den sich „,vielleicht zum erstenmal alle Bewohner dieses Staates, der viel weniger und viel mehr als ein Staat gewesen ist, als Österreicher" fühlen konnten ${ }^{34}$. Doch lässt sich diese Trauerarbeit generalisieren?

Ungeachtet einer emotional-emphatischen Involvierung in das Kriegsgeschehen kam es bei dem „Erfinder des Prager Kreises ${ }^{35 “}$ zu einer raschen Neuorientierung ${ }^{36}$. Max Brods kulturpolitisches Engagement richtet sich zunächst auf die neue Republik als Nachfolgestaat des multikulturellen und -konfessionellen Habsburg und damit auf die Frage, wie ein "Gleichgewicht zwischen den verschiedenen Nationen" in der Tschechoslowakei herzustellen sei $^{37}$. Brod bemühte sich insbesondere um eine Überwindung nationaler Polarisierung, allerdings erfolgte mit der nach dem Krieg einsetzenden Positionierung vor allem eine Neubestimmung für die Juden in der ČSR zwischen Deutschen und Tschechen und jenseits assimilativer oder diasporischer Einstellungen ${ }^{38}$. Brods Konzept einer Kulturverwandtschaft durch „Sprache, Erziehung, Lektüre, Kultur", welches eben keine „Blutsverwandtschaft“ sei $^{39}$, besitzt dabei eine auf die

34. Kurt Krolop, Klaas-Hinrich Ehlers, Steffen Höhne und Marek Nekula (Hg.), Studien zur Prager deutschen Literatur, Wien, Praesens, 2005, S. 37.

35. Steffen Höhne, Anna-Dorothea Ludewig, Julius H. Schoeps (Hg.), Max Brod (18841968). Die Erfindung des Prager Kreises, Köln, Weimar, Wien, Böhlau (= Intellektuelles Prag im 19. und 20. Jahrhundert, Bd. 9), 2016.

36. Eine solche emotionale Involviertheit findet man auch - zumindest vereinzelt - bei Kafka, was eine einschlägige Tagebuchstelle belegen kann: „Die Artillerie, die über den Graben zog. Blumen, Heil und Nazdarrufe. Das krampfhaft stille, erstaunte aufmerksame Schwarze und schwarzweiße Gesicht. - Ich bin zerrüttet statt erholt. [...] Patriotischer Umzug. Rede des Bürgermeisters. Dann Verschwinden, dann Hervorkommen und der deutsche Ausruf: ,Es lebe unser geliebter Monarch, hoch.' Ich stehe dabei mit meinem bösen Blick. Diese Umzüge sind eine der widerlichsten Begleiterscheinungen des Krieges. Ausgehen von jüdischen Handelsleuten, die einmal deutsch, einmal tschechisch sind, es sich zwar eingestehen, niemals aber es so laut herausschreien dürfen wie jetzt." (Kafka, Franz, Tagebücher. Kritische Ausgabe, hrsg. von Hans-Gerd Koch, Michael Müller und Malcolm Pasley (Schriften, Tagebücher, Briefe), Frankfurt/Main, Fischer, 1990, S. 545-547 $-6.8 .1914)$

37. Gaëlle Vassogne, Max Brod in Prag: Identität und Vermittlung, Tübingen, Niemeyer, 2009; Steffen Höhne, „Max Brod als Prager Kulturmittler. Konzepte des Kulturtransfers um 1918 zwischen Profession und Mission“, in Zts. für Interkulturelle Germanistik 5/2, 2014b, S. 87-102.

38. Gaëlle Vassogne, Max Brod in Prag: Identität und Vermittlung, S. 10.

39. Max Brod, „Ein menschlich-politisches Bekenntnis. Juden, Deutsche, Tschechen.“, in 
Politik bezogene antideutsche Diktion, habe Brod doch als „deutschsprechender Jude“ eben „nur an der deutschen Sprachlichkeit dieser Institu-

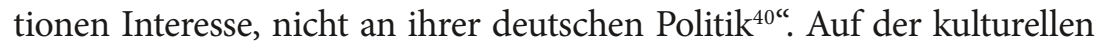
Ebene bleiben Vorstellungen von Multinationalität und interethnischer Mittlerfunktion konstitutiv für die Prager jüdischen Intellektuellen, was sich bei Brod in der „Verteidigung der Mitte“, mit der eine neutrale Mittelstellung der Juden zwischen Tschechen und Deutschen postuliert wurde, genauso zeigt wie im literarischen Werk. Mit dem aus diesen Überlegungen abgeleiteten Konzept eines den Nationalismus substituierenden Nationalhumanismus, eine Art gereinigter Nationalismus, soll dabei nicht nur der Weg der kulturellen Vermittlung eröffnet werden, sondern auch der einer kosmopolitischen Perspektivierung mit der Pflicht freiwilligen Opfers nationaler Interessen zugunsten der Menschheit [...]. Mit aller Schärfe muß diesem heutigen Nationalismus, der den Kultur- und Geisteswert des Volkstums zu kapitalistischer Pleonerie vergewaltigt, ein neuer Nationalismus entgegengesetzt werden ${ }^{41}$.

Der Versuch, essayistisch die Stellung der jüdischen Bevölkerung in der ČSR argumentativ zu stützen und zugleich eine zionistische Option $\mathrm{zu}$ antizipieren, korrespondiert mit dem literarischen Werk, in dem ebenfalls das Thema Entfremdung nach 1918 aufgegriffen wird. Als Beispiel sei der Roman Zauberreich der Liebe (1928) gewählt, in dem der Protagonist Christof Nowy mit durchaus biographischen Implikationen Brods seine isolierte Stellung zwischen den Nationen reflektiert:

Nicht dass Christof eine Abneigung gegen die Tschechen gehabt hätte. Im Gegenteil, er bewunderte ihre mit jugendlichem Elan und schöner Selbstkritik aufsteigende Kultur - und einige ihrer urkräftigen genialen Menschen, ja das ganze einfache Volk liebte er geradezu. Mit tschechischen Liedern, tschechischer Musik war er aufgewachsen. Seine Familie, seit undenklichen Generationen in Prag erbgesessen, gehörte zu denen, in denen deutsches und tschechisches Blut sich mischte. Ein Zweig der Familie war sogar ganz tschechisch gesinnt und schrieb sich in korrekterer Orthographie „Novy“, nicht (wie er) Nowy ${ }^{42}$.

Diese Tschechophilie brachte ihn schon vor dem Krieg in Distanz zu den Herrschenden, damals der deutschen Elite, wobei er sich nach 1918 von der neuen Elite gleichermaßen distanzierte:

Die neue Rundschau. XXIX. Jg. Der freien Bühne (Bd. 2), Berlin, Fischer, 1918, S. 15801593, hier S. 1581f.

40. Brod, ebd., S. 1584.

41. Ebd., S. 1591f.

42. Max Brod, Zauberreich der Liebe. Roman, Berlin, Wien, Leipzig, Zsolnay, 1928, S. $26 f$. 
Von den ehrgeizigen Politikern, die das Deutschtum in Prag völlig austilgen wollten wie einen nicht hereingehörigen Fremdkörper, wich er mit Schaudern zurück. Daß das Recht, zur Macht gelangt, gleich wieder sein Maß überschreiten, ins Unrecht hinüberpendeln muß, - bitter, dies mitzuerleben. Aber mich, den alten Prager, in Prag als Fremdkörper erklären zu wollen, - welch ein Unsinn obendrein zu aller Brutalität ${ }^{43}$.

Beklagt wird explizit die seit dem Untergang der Habsburgermonarchie $^{44}$ sich durchsetzende nationale Identifikation mit ihren klaren Exklusions- und Inklusionsvorstellungen und ihren sprachpuristischen Zumutungen, die ein Drittes, ein Identitätsmodell des Hybriden jenseits der national kategorisierten Gruppe nicht zulassen:

Diese gleichsam private Alt-Prager Mischung, dieses nicht im politischen Sinn, aber in der Kultur Altösterreichische oder Böhmische (ein aussterbender Begriff, der jenseits von deutsch und tschechisch liegt, der beide, wenn auch als feindliche oder zumindest fremde Brüder umschließt), diese Luft seiner geliebten Barockfassaden, seiner bronzeglänzenden Abendhimmel hinter dem Laurenziberg, - wer teilte das noch mit ihm ${ }^{45}$ !

43. Brod,ZauberreichderLiebe, S.27.IndieDebatteinnerhalbdes PragerKreisesumrechtsstaatliche, auf nationale Rechte bezogene Prinzipien waren weitere Intellektuelle involviert. Erwähnt sei hier nur das publizistische Wirken von Johannes Urzidil, der - unter Anknüpfung an die habsburgischen Traditionen - an Konzepte eines föderalistischen Nationalitätenstaates anknüpfte. Gegen den zentralistisch organisierten, partiell antideutsch eingestellten Nationalstaat ČSR und angesichts der kulturpolitischen Benachteiligung der Minderheiten propagierte Urzidil das Modell eines auf Ausgleich bedachten Nationalitätenstaates. Ursache für sprachnationale Konflikte in der Republik sei der Wechsel von einem positivistischen böhmischen Staatsrecht zu einem negativistischen mit seiner Politik der Entösterreicherung: „Der neue Staat entstand aus einer doppelten Negation. Aus der inneren Negation des zentralistischen Österreich durch die Tschechen und aus der äußeren Negation Deutschlands durch die Westmächte" (Johannes Urzidil, „Tschechen und Deutsche“, in Oskar Bie, S. Fischer und S. Saenger (Hg.), Die Neue Rundschau, Berlin, Leipzig, Fischer, 1922, S. 157-176, S. 158f.); s. ferner Steffen Höhne, „Johannes Urzidil im Spannungsfeld von Kultur und Politik“, in Ders., Klaus Johann, Mirek Němec (Hg.), Johannes Urzidil (1896-1970). Ein „hinternationaler“ Schriftsteller zwischen Böhmen und New York Köln, Weimar, Wien, Böhlau (= Intellektuelles Prag im 19. und 20. Jahrhundert, Bd. 4), 2013, S. 53-73.

44. $\mathrm{Zu}$ der Modellfunktion für Habsburg, die entweder als übernationale Staatskonstruktion (so Adolph Fischhof) oder als paradigmatisches Modell kleiner Staaten (so František Palackýund Karel Havlíček-Borovský) auf die Situation in den Böhmischen Ländern übertragen wurde, s. Michael Havlin, Die Rede von der Schweiz. Ein medial-politischer Nationalitätendiskurs in der Tschechoslowakei 1918-1938 (= Die Deutschen und das östliche Europa - Studien und Quellen, 8), Frankfurt/Main u. a., Lang, 2011. Eine Fortsetzung fand diese Debatte im Ersten Weltkrieg, stellvertretend sei hier Karl Renners Modell der Donaumonarchie als ein Nationalitätenstaat bzw. seine Vision einer „Weltschweiz“ genannt und als Gegenmodell Masaryks Konzept der kleinen Nation, ein „,apologetischer Nachweis der Ebenbürtigkeit kleiner Nationen und Kulturen." (Havlin ebd., S. 84)

45. Max Brod, Zauberreich der Liebe, S. 28. Später heißt es, die spezifisch Prager Hybridität 
Dieses allen nationalpuristischen Vorstellungen widersprechende Hybriditätsideal, das von weiteren Prager Zionisten wie Hugo Herrmann und Hans Kohn vertreten wird ${ }^{46}$, greift auf Erfahrungen vor 1918, aber auch auf Erfahrungen der multinationalen ČSR zurück. Es sind gleichwohl idyllisierende Rückblicke Brods auf die habsburgische Zeit, die Brod seinen Protagonisten werfen lässt. Die neue Zeit nach 1918 wird als Entwurzelung und Entfremdung wahrgenommen, die zu einer Abwanderung Prager deutscher Autoren aus der Stadt führten ${ }^{47}$ und die für nicht wenige Prager deutsche Intellektuelle charakteristisch waren:

Ein Fremdkörper in Prag! Laßt euch nicht auslachen! Ihr baut vielleicht die besseren Bankpaläste und Postsparkassen-Scheckämter, da kann ich mit euch nicht Schritt halten, - aber was das Besitztum einer alten, heimlichen, unoffiziellen, dem wehmütigsten Gefühl entstiegenen Melodie betrifft, aus diesem Besitztume kann ich nicht vertrieben werden $[\ldots]^{48}$

Auch Franz Kafka dokumentiert diese Erfahrung von Isolation, wenn er Robert Klopstock Ende März 1923 von seiner existentiellen Angst berichtet, die aus seiner nationalen, physischen und individuellen Position resultiere: „Ein Jude und überdies deutsch und überdies krank und überdies unter verschärften persönlichen Umständen $[\ldots]^{49}$. “ Topologischer Bezug ist dabei Prag, jenes ,Mütterchen mit Krallen', dem auch der Brodsche Held zu entkommen sucht:

Der Barockstil ist das Böse. Und Prag - die Stadt des Barock, Prag ist die böse Stadt. Prag macht alle böse, die hier wohnen. Die Stadt mit der schlechten Luft, dumpfig im Kessel gelegen, immer ist sie eine Stadt der Unterdrücker gewesen. Stadt der Habsburgsklaven, der Kirchensklaven, Stadt der nationalen Haßausbrüche seit je, der Eroberer und der Besiegten. Bald die Deutschen, bald die Tschechen oben, immer Unterdrückung ${ }^{50}$.

akzentuierend: „Christoph fühlt sich als Halbblut, nicht tschechisch und nicht deutsch, die besondere Spezies: Prager [...]." (Brod, Zauberreich der Liebe, S. 250)

46. Dimitry Shumsky, Zweisprachigkeit und binationale Idee. Der Prager Zionismus 19001930, Göttingen, V\&R, 2013, S. 244.

47. Zum Gefühl von Heimatlosigkeit in Prag nach 1918 s. Franz Werfel, „Warum haben Sie Prag verlassen?", in ders., Zwischen oben und unten. Aufsätze, Aphorismen, Tagebücher, literarische Nachträge, hrsg. von Adolf D. Klarmann, München, Wien, Langen Müller, 1975 [1922], S. 592; ferner den Beitrag von Kurt Krolop „Hinweis auf eine verschollene Rundfrage; „Warum haben Sie Prag verlassen?“ (Krolop, Studien, S. 89-102).

48. Brod, Zauberreich, S. 29.

49. Franz Kafka, Max Brod (Hg.), Briefe 1902-1924, Frankfurt/Main, Fischer, 1975, S. 430.

50. Brod, Zauberreich der Liebe, S. 102f. S. in diesem Kontext den Topos einer als durch das als imperialer Herrschaftsstil wahrgenommene Barock und einer damit als berückend 
Die Lösung, die Brod in seinem Kafka-Roman antizipiert, ist dann folgerichtig die jüdische Landnahme in Palästina, auch wenn deren nationalistische Geburtswehen den Protagonisten Nowy zunächst abschrecken. Ausgehend von dem Niedergangsnarrativ der jüdischen Kultur, nach dem die „Kraft der jüdischen Rasse [...] völlig erschöpft“ sei $^{51}$, wird die Situation in Palästina zunächst distanziert betrachtet, zumal dort die gleichen Exklusionsmechanismen wie in Europa wahrgenommen werden: „Chauvinismus. Genau so wie bei uns in Prag, wo man die deutschesten Dörfer mit tschechischer Umbenennung glücklich macht. [...] Wenn der ganze europäische Nationalitäten-Dreck mitherüberverpflanzt wird, - statt Duldsamkeit Gewalt ${ }^{52}$.“

Je mehr er sich jedoch mit der Situation vertraut macht, umso faszinierender erscheint der Versuch einer neuen, zionistischen Gemeinschaft, woran dann auch das literarische alter Ego Kafkas maßgeblichen Anteil besitzt. In Kontakt mit den zionistischen Bauern und nicht zuletzt mit dem Kafka-Wiedergänger Erich Garta, der jüngere Bruder von Richard Garta ${ }^{53}$, gelangt auch Christoph zur Erkenntnis: „Was ihm vordem ,Strafkolonie dünkte, wird ihm jetzt zu einem Gnadenfall ${ }^{54}$.“ Brods literarisches Werk korreliert dabei mit der binationalen Sozialisation der Prager Zionisten zwischen Bar Kochba (1899) und Brit Schalom (1925), u. a. Hugo Herrmann, Hans Kohn, Robert Weltsch, Leo Hermann und eben Max Brod, die das Schlüsselkonzept des „Brückenschlags“ zwischen den Kulturen sowohl auf die ČSR als auch

konnotierten Atmosphäre Prags, z. B. bei Ernst Weiß aus dem Jahr 1933: „Über dem jungen, lebensfreudigen und lebenswilligen Prag lastet der Geist der Gotik und mehr noch, alles andere bedrückend, oft erdrückend, der Geist des habsburgischen Barock wie eine uralte Fürstin mit versteinerten, immer noch schönen Zügen, die alle Urenkel überlebt hat, allen Reichtum besitzt und auf deren Tod niemand zu hoffen wagt." (Ernst Weiß, „Prag“, in Ders., Die Ruhe in der Kunst. Ausgewählte Essays, Literaturkritiken und Selbstzeugnisse 1918-1940, Berlin, Weimar, Aufbau, 1987 [1933], S. 207-210, S. 207).

51. Max Brod, Zauberreich der Liebe, S. 390.

52. Ebd., S. 235. „und schon vergewaltigt man die Araber, zumindest ihren alten Namen, o er kennt das, kennt den Kleinkampf der Sprachengrenze, offizielle Ortsnamen sind Symbol.“ (ebd., S. 236)

53. Richard Garta fungiert im Roman als der verstorbene Franz Kafka, dessen Bruder Erich Garta die zionistische Option, die Kafka nach Brod vertreten haben soll, im Roman umsetzt. „Die mystische Grundzuversicht Richards schwebt über der Barackenstadt: daß selbst tiefste Ironie, schmerzlichste Kritik letzten Endes den natürlichen Wuchs des Guten nichtschädigt." (ebd., S. 411) Zu Brods Versuchen, per Deutungsmonopol Kafka als Zionisten zu tradieren s. die Beiträge in dem Sammelband Höhne, Ludewig, Schoeps, Max Brod (1884-1968).

54. Brod, Zauberreich der Liebe, S. 410. 
auf einen zu gründenden jüdischen Staat in Palästina, der als Nationalitätenstaat sowohl die Nachfolge der Habsburgermonarchie bzw. - nach 1938 - auch die Nachfolge der Tschechoslowakei anzutreten habe. Das Ideal eines binationalen staatlichen Ordnungsrahmens wird in Brods Roman aus Mitteleuropa in den Orient transferiert ${ }^{55}$.

\section{Ludwig Winder}

Ludwig Winder, dessen sämtliche Erzählwerke einen „eigensinnigen Handlungsablauf“ besitzen und die alle „Figurenromane“ mit „Dominanz einer Mittelfigur oder eines Paares" sind ${ }^{56}$, fand erst nach Kafkas Tod Aufnahme im Prager Kreis - und dies als „dezidierter Nicht-Zionist ${ }^{57}$. Schildert Winders Erstlingsroman Die rasende Rotationsmaschine (1917) die Welt der Wiener Presse vor und um 1914, so reflektieren die noch expressionistisch beeinflussten Texte (Die jüdische Orgel, 1922; Hugo, die Tragödie eines Knaben, 1924) traumatische Kindheitserlebnisse. In der Jüdischen Orgel bzw. in dem als Kommentar zu lesenden Text Geschichte meines Vaters steht die Gestalt des „harten, furchterregenden Vaters ${ }^{58 "}$ im Zentrum. Erzählungen wie Legende vom häßlichen Menschen (1922/23), Ledowksi (1923) und Turnlehrer Pravda (1924), nach dem Prinzip der „Parallelität und Steigerung“ aufgebaut ${ }^{59}$, verarbeiten Erfahrungen von Hässlichkeit. Turnlehrer Pravda fand Eingang in Hugo, die Tragödie eines Knaben. Winders Frühwerk, das sich immer auch mit Fragen der Ausprägung jüdischen Lebens befasst, bildet einen "ganz unverwechselbaren Stil" heraus, mit ihm schließt sich ein Stoffund Themenkreis, der mit Die nachgeholten Freuden (1927) als erste deutschsprachige Gestaltung der „tschechoslowakischen Nachkriegs-

55. Shumsky, Zweisprachigkeit, S. 302, akzentuiert dabei das dialogische Moment, welches dem zionistischen Modell zugrunde liege: „Mit der Einwurzelung des Zionismus in die Landschaft des Vorderen Orients werden Elemente der arabischen nationalen und kulturellen Umwelt zwangsläufig zu Bestandteilen des jüdisch-nationalen Seins, auch die lokalen arabischen Nationalitäten, in deren Mitte sich eine andere Nationalität angesiedelt hat, bleiben nicht, arabisch' im engeren national-ethnischen Sinne des Wortes, vielmehr erweitert sich ihre nationale und kulturelle Existenz - insbesondere in Palästina - so, dass sie die Beeinflussung durch die jüdisch-zionistische Nachbarkultur mit einschließt."

56. Kurt Krolop, Ludwig Winder, S. 98.

57. Ebd., S. 200.

58. Ludwig Winder, Geschichte meines Vaters, Paderborn, Igel, 2000, S. 12.

59. Kurt Krolop, Ludwig Winder, S. 186. 
welt $^{60 \text { ", }}$ von einer Reihe von Nachkriegsromanen abgelöst wird. Dieses Nachkriegswerk ist implizit immer auch eine Auseinandersetzung mit der alten, überkommenen, delegitimierten Welt vor 1914, auf die kein nostalgischer Blick geworfen wird, sondern die als Folie aktueller sozialer Verwerfungen nach 1918 herangezogen wird.

In den Romanen Nachgeholte Freunden und Dr. Muff wird explizit die Umbruchsituation nach 1918 gestaltet $^{61}$, womit zugleich eine Abrechnung mit der Welt der Väter und den überkommenen Herrschaftsstrukturen der Vorkriegszeit erfolgt. Winder legt dabei keine Hoffnung auf eine kommunistische Alternative (wie Weiskopf im Slawenlied), auch wenn die Zeit nach 1918 keineswegs mit Fortschritt und sozialer Sicherheit verbunden erscheint, sondern eine pessimistische Sicht überwiegt. An die Stelle alter Gewissheiten vor 1914 tritt eine Desorientierung und Skrupellosigkeit, in der alte moralische Werte und Normen sowie soziale Bindungen vollkommen unterminiert werden. Der Protagonist Adam Dupic, einen „Menschenfeind ${ }^{62 “, ~ d e r ~ d a n a c h ~ s t r e b t, ~ „ G o t t ~}$ ähnlich zu werden ${ }^{63 “}$, und der in Boran eine kleine Welt gottgleich $\mathrm{zu}$ beherrschen versucht ${ }^{64}$, wird als paradigmatischer Typus des Kriegsgewinnlers und Spekulanten skizziert, für den die Welt nur ein „Spekulationsobjekt" darstellt ${ }^{65}$. Erst durch den Zusammenbruch der sozialen und moralischen Hierarchien kann dieser neue Nachkriegstypus

60. Ebd., S. 65.

61. In den Nachgeholten Freuden liefert Winder eine präzise zeitliche Strukturierung. Der erste Teil des Romans datiert - nebst Rückblenden zur Geschichte Dupic' - vom 2.7.1918 bis zum 31.10.1918; der zweite vom November 1918 bis zum 15.10.1919; der dritte vom Juli 1920 bis zum 25.10.1926. Zum Roman s. Margarita Pazi, Fünf Autoren des Prager Kreises, Frankfurt/Main u. a., Lang, 1978, S. 256-298; hier auch Verweis auf Analogien zu Bata (ebd., S. 276) und Judith von Sternburg, Gottes böse Träume. Die Romane Ludwig Winders, Paderborn, Igel, 1994.

62. Ludwig Winder, Die nachgeholten Freuden, Wien, Hamburg, Zsolnay, 1987 [1927], S. 56, 62.

63. Winder, Die nachgeholten Freuden, S. 79.

64. S. z. B. das Gespräch mit dem Sohn: „Du bist nach Boran gekommen, um hier Gottes Stelle einzunehmen. Gott ist der größte Verbrecher: das ist dein Glaube. Du willst Deinem Gott gleichen.", Winder, ebd., S. 165.

65. Winder, ebd., S. 240. Dies wurde schon in den zeitgenössischen Rezensionen erkannt. Albert Ehrenstein schrieb in der Berliner Zeitschrift Die Dame (Nr. 9, 1929) von einem „südslawischen Raffke, sadistisch und drollig“; Fritz Gaupp nannte Dupic in der Berliner Vossischen Zeitung. (12.12.1927) einen „Usurpator, Teufel, Halbgott“; Ferdinand Deml im Witiko (1929: 107) von einer „,vollsaftigen Bauerngestalt“. Weitere Besprechungen von Robert Hohlbaum in der Deutschen Zeitung. Bohemia (21.12.1927); Walter Angel in der Wiener Neuen Freien Presse (13.5.1928); Josef Mühlberger im Witiko (1928) und Paul Leppin in der Prager Hohen Warte (Dezember 1931). 
seine Macht entfalten. Er steht am Übergang von alter habsburgischer und neuer tschechoslowakischer Ordnung, wobei er den Niedergang früher als andere erkennt ${ }^{66}$, wie er auch als einziger die Möglichkeiten der zukünftigen Gesellschaft erahnt ${ }^{67}$. Dupic wird zum Repräsentanten einer ungeregelten Nachkriegsordnung ${ }^{68}$, dem es mit den Werkzeugen Geld, menschliche Gier und Bequemlichkeit gelingt, sich die kleinstädtische Gesellschaft mit Hilfe ausbeuterischer Methoden von sich abhängig zu machen und völlig zu unterwerfen ${ }^{69}$. Es gibt nur einen Kriegsgewinnler, alle anderen scheinen Verlierer zu sein, wie Domansky, einer der Arbeiter aus Boran erkennen muss:

Deshalb begreif ich nicht, daß sich die Leute jetzt alles gefallen lassen, also ob nichts gewesen wär'. Da kommt man aus dem Krieg nach Haus und denkt sich: Jetzt ist aber Schluß! Und da sieht man, daß es noch viel ärger ist als vorher. Da sieht man, daß alles noch viel niederträchtiger ist als früher. Was ihr Vater hier treibt, das hätte er sich vor dem Krieg schwerlich erlaubt ${ }^{70}$.

Doch weder der Widerstand seitens des christlichen Sohnes Peter, noch des kommunistischen vertreten durch den Sohn des jüdischen Schullehrers Karl Buxbaum, noch die kapitalistische Konkurrenz durch Elsa Buxbaum können die Karriere von Dupic aufhalten, zumal auch die neue staatliche Ordnung offenbar aus ökonomischen Zwängen heraus keine Grenzen zu setzen vermag. Hinzu kommt, dass sich der Protagonist geschickt jenseits nationaler Zuschreibungen zu verorten

66. Ludwig Winder, Die nachgeholten Freuden, S. 122.

67. Ebd., S. 106.

68. „Schlechte Zeiten, ganz miserable Zeiten! Leute, die vor dem Krieg in zerrissenen Hosen herumgelaufen sind, fahren jetzt im eigenen Auto, während ein Colloredo-Mansfeld mittels Inserats um einen Sekretärposten ansuchen muß.", ebd., S. 182.

69. Der Gipfel einer perfiden ökonomischen Ausbeutung und moralischen Korrumpierung wird mit der Errichtung eines immer Kredit gewährenden „Volkshauses“, eigentlich ein Bordell, erreicht: „Die Tage vor der Lohnauszahlung waren die gefährlichsten. Zerschlagen von der Arbeit, stand man mit leerer Tasche auf der Straße. Die dunkle Kleinstadt war ausgestorben, trübselig der Heimweg, trostlos der Gedanke an die Abendstunden. Was gab es da zu überlegen? Nur im Volkshaus war man mit leerer Tasche willkommen. [...] Niemand war genötigt, an Geld zu denken. Das Essen, das Trinken, die Liebe: alles war ohne Geld zu haben, jeder hatte Kredit. Das Essen, das Trinken, die Liebe: alles wurde gebucht von Dupics Kellnern, verflucht von den Frauen und Kindern, die zu Hause hungerten und froren.", ebd., S. 318f. Schon vorher heißt es: „Nun erst komme Sodom und Gomorrha. Nun erst werfe sich der Teufel mit voller Wucht den Menschen entgegen.", ebd., S. 299.

70. Ebd., S. $217 f$. 
wei $\Re^{71}$. Letztlich artikuliert Winder sowohl Kritik am Zeitalter des bindungs- wie traditionslosen Individuums ${ }^{72}$, wie an der unpolitischen, orientierungslosen, angesichts neuer Kontingenzen völlig überforderten Masse ${ }^{73}$, durch die sich die neue Gesellschaft von der traditionsverhafteten alten fundamental abgrenzt ${ }^{74}$.

Ähnlich erfolgt in der Reitpeitsche (1929) eine „Bloßstellung der wirtschaftlichen Grundsituation der ersten Nachkriegsjahre und der in diesem Klima gedeihenden waghalsigen Spekulationen und Erfolgsmöglichkeiten ${ }^{75}$." Die in diesen Texten latent und manifest enthaltenen Vater-Sohn-Konflikte ${ }^{76}$, in der Reitpeitsche zudem in das Offiziersmilieu verlegt, strukturieren auch den Roman Dr. Muff mit dem Paria und Kriegsgewinnler Garber ${ }^{77}$. Winders Nachkriegswerk diskutiert auf der psychologischen Ebene die Möglichkeit von sozialer Bindung und Liebe, auf sozialhistorischer und politischer Ebene die Verwerfungen der neuen, nachhabsburgischen Gesellschaften, auf theologischer

71. „Dupic erwiderte, er sei Pensionist und gedenke in Boran das Leben eines Pensionisten zu führen, um Politik kümmere er sich nicht, ihm seien alle Menschen, Deutsche und Tschechen, Juden und Christen, gleich sympathisch.“, ebd., S. 99. Allerdings hält dies ihn nicht davon ab, wenn es opportun erscheint, sich ethnisch zu kategorisieren: „Ich bin Slave“ (ebd., S. 100), um letztlich eine Zuordnung zu vermeiden: „Noch immer wußte man nicht genau, ob er mit den Deutschen oder mit den Tschechen, mit nationalen oder sozialistischen Parteien paktiere. Jedem Parteimann gab er in allem recht, alle lachte er aus.", ebd., S. 278.

72. „Da hat es jahrzehntelang eine erfolgreiche Arbeiterbewegung gegeben, da ist jahrzehntelang in sogenanntes Klassenbewußtsein in der Arbeiterschaft geweckt worden, in mehreren Staaten sind die Arbeiter sogar zur Regierung gelangt - und ein einziger Mensch bringt es mit Leichtigkeit fertig, alle Gesetze der Zeit umzustoßen.", ebd., S. 260.

73. „Die meisten Menschen [...] leben verantwortungslos im Tempo unserer Zeit, ohne die Mächte, deren Spielball sie sind, überhaupt zu erkennen.“, ebd., S. 264.

74. Eine „Fortsetzungsbeziehung" nimmt der folgende Roman Dr. Muff (1931) ein, der das Motiv des hemmungslosen Machtmenschen wiederaufnimmt (Pazi, Fünf Autoren, S. 278).

75. Pazi, ebd., S. 280. S. a. Jindra Broukalová, „Verwandlungen vor dem Gericht. Zur Betrachtung der Verwandlungen im Vater-Sohn-Konflikt in Franz Kafkas Erzählung ,Das Urteil" und in Ludwig Winders Roman ,Die Reitpeitsche“", in brücken N.F. 24 (2016), 2017, S. 165-198.

76. In den Nachgeholten Freuden s. z. B. die Passagen ebd., S. 242 und 279.

77. Äquivalent zu den Herrschergestalten fungiert die Figur des Kammerdieners (1942/43), die in der Pflicht eine radikale Umwertung findet und mit der eine Kernfrage des Prager Kreises individualisiert wird, „die Bewährungsprobe des vor die freie Wahl gestellten Menschen zwischen der ,richtigen und der guten Tat"“ (Pazi, Fünf Autoren, S. 289), womit zugleich eine positive Umdeutung der Kammerdiener-Figur erfolgt. Die Figur des Kammerdieners wurde von Winder erstmals in dem unveröffentlichten Schauspiel Der Kaiser stirbt (um 1929) ausgeführt, vgl. Arno A. Gassmann, Lieber Vater, Lieber Gott? Der Vater-Sohn-Konflikt bei den Autoren des engeren Prager Kreises (Max Brod, Franz Kafka, Oskar Baum, Ludwig Winder), Oldenburg, Igel, 2002, S. 242. 
Ebene die Neubestimmung von Gut und Böse in einer Zeit der Entwertung aller Werte: „Das Böse und das Gute, alles hatte nur den einen Zweck, den Menschen zur Sünde zu verführen ${ }^{78}$.

\section{Habsburg-Renaissance nach 1933}

Standen bis 1933 in den publizistischen und literarischen Diskursen des Prager Kreises Fragen der Kooperation zwischen den Kulturen bzw. der Regelung der Verhältnisse zwischen Minderheit und Mehrheit im Zentrum und damit immer auch Überlegungen, wie Traditionen und Erfahrungen aus der habsburgischen Phase in die Tschechoslowakei zu übertragen wären, so erhält die Reflexion der Habsburgermonarchie ab 1933 eine neue, auch ideologische und ordnungspolitische Konnotation $^{79}$. Angesichts der wachsenden nationalsozialistischen Bedrohung, die ab Mitte der 1930er Jahre die Stabilität Mitteleuropas zunehmend in Frage stellte, knüpft Franz Werfel mit dem Essay Ein Versuch über das Kaisertum Österreich aus dem Jahr 1936 an eine das nationalistische und rassistische Denken einhegende supranational-austriazistische Tradition an. Das sacrificium nationis, die „Selbstaufopferung der Nationalität" wird zum habsburgischen Charakteristikum und zu einem Modell für die europäische Zukunft, schließlich heiße Österreicher zu sein, „alles Blutgebundene, Instinktmäßige, Dämonische überschritten zu haben und zum abendländischen Allmenschen umgeschaffen worden zu sein in der Lehre des Reiches. Der „wahre Österreicher“, so Werfel, könne „immer nur ein gelernter Österreicher sein ${ }^{80 “}$. Beklagt wird somit

78. Ludwig Winder, Die nachgeholten Freuden, S. 301.

79. Franz Werfel, „Ein Versuch über das Kaisertum Österreich“, in Adolf D. Klarmann (Hg.), Zwischen oben und unten. Aufsätze, Aphorismen, Tagebücher, literarische Nachträge, München, Wien, Langen Müller, 1975 [1937], S. 493-520, hier S. 517. Zur bereits Mitte der 1920er Jahre erfolgten Wendung zu einer positiven Darstellung der Habsburgermonarchie in Werfels Erzählungen wie Der Tod des Kleinbürgers (1926) mit dem aus Böhmen stammenden Antihelden, dem „optierten österreichischen Staatsbürger Fiala" (Franz Werfel, Die Tanzenden Derwische. Erzählungen, Frankfurt/Main, Fischer, 1989, S. 128), Das Trauerhaus (1927), Geheimnis eines Menschen (1927), Die Hoteltreppe (1927) und Die Entfremdung (1927) s. Norbert Abels, „Erinnerungsschatten und Weltdämmerung. Anmerkungen zu Franz Werfels Erzählkunst“, in Michael Schwidtal, Václav Bok (Hg.), Jugend in Böhmen. Franz Werfel und die tschechische Kultur - eine literarische Spurensuche, Wien, Praesens, 2001, S. 85-109. Im Trauerhaus fungiert ein Bordell als „Spiegelbild des zerfallenden Ganzen“ (ebd., S. 97), ein „metaphorischer Raum eines Weltuntergangs." (ebd., S. 93)

80. Zum Diskurs um den „österreichischen Menschen“ und über die Eigenart der österreichischen Kultur als Begleiterscheinungen zum Untergang des Habsburgerreiches 
neben dem Verlust einer in Habsburg verkörperten höheren Ordnung insbesondere die „Auslöschung der Würde des Individuums ${ }^{81 “}$. Gegen die rassistische reichsdeutsche Blut-und-Boden-Ideologie erhält die Habsburgermonarchie auch historisch gesehen eine höhere politische Legitimation, da es als das eigentliche Reich eine höhere Idee verkörpere, durch die es sich fundamental vom Deutschen Reich, ein bloßer Nationalstaat, abgrenze:

Nur im Zeichen einer höheren Idee wurden und werden Reiche gegründet. Nationen können bloß Staaten bilden. Nationalstaaten sind ihrem innersten Wesen nach dämonische Einheiten; wie alles Dämonische und Abgöttische reizbar, "dynamisch“, drohend und bedroht. Die wahren Reiche aber entstehen dadurch, daß den dämonisch-natürlichen Einheiten ein übernationales-göttliches Element zugemischt wird, das sie über sich emporreißt: eine Offenbarung oder eine höhere Idee. Jedes echte Reich ist ein mißlungener Versuch, das Reich Gottes auf Erden zu stiften. In seiner Geburtsstunde wenigstens ist es das ${ }^{82}$.

Habsburg wird mit christlicher Konnotation zum legitimen, antiimperialen, zum machtpolitisch betrachtet konstitutiv Anderen, wogegen es den Hohenzollern widerrechtlich gelungen sei,

die deutschen Kleinstaaten unter ihre Herrschaft zu bringen. [...] Und nun folgte einer der übelsten Wortwitze der Weltgeschichte. Großpreußen nannte sich „deutsches Reich“, da es doch bestenfalls nur ein Nationalstaat, eine dämonische Einheit war, das Gegenteil also eines völkerverbindenden, aus einer übergeordneten Idee geborenen Reiches. Die preußischen Könige aber verliehen sich den Titel von Kaisern. [...] Jeder Kaiser ist ein Nachfolger Caesars, der die supernationale Weltherrschaft abendländischer Geistung begründete. Caesarentum ist der absolute Gegensatz zum Stammeskönigtum. Die Hohenzollern waren erfolgreiche Stammeskönige, die aus Haß gegen die legitimen Caesaren des Hauses Habsburg einen leeren Kaisertitel usurpierten ${ }^{83}$.

Das Österreich der 1930er Jahre, das nicht als Nationalstaat, sondern als Erbe der Habsburgermonarchie verstanden wird ${ }^{84}$, stehe seit 1804 in einer supranationalen Tradition. Dieses Deutungsmuster präzisiert

s. William M. Johnston, Der österreichische Mensch. Kulturgeschichte der Eigenart Österreichs, Wien, Köln, Graz, Böhlau, 2010.

81. Abels, ebd., S. 86.

82. Werfel, „Ein Versuch über das Kaisertum Österreich, S. 496.

83. Ebd., S. 502. Thematisch knüpft Werfel an die Preußen-Kritik an, die bereits von Franz Grillparzer formuliert wurde, bei dem es zur Reichsgründung 1817 heißt: „Ihr glaubt, ihr habt ein Reich geboren, und habt doch nur ein Volk zerstört."

84. Von Werfel siehe ferner den Essay Heimkehr ins Reich, erschienen am 1.2.1939 in der Österreichischen Post in Paris. 
Werfel in späteren Texten: in der zunächst unveröffentlichten Skizze Das Ostreich (1938) und in dem Essay Les deux Allemagne, erschienen am 16. September 1939 im Neuen Tage-Buch in Paris, in dem die Forderung nach einer Revision von Trianon und St. Germain erhoben wird. Angesichts der nationalsozialistischen Bedrohung müsse die Zerstörung des europäischen Gleichgewichts, „der fehlerhafte Lauf der Geschichte [...] rückgängig gemacht werden ${ }^{85 “}$. Stattdessen müsse „dem preußischen Gravitationssystem ein anderes, nunmehr doppelt so starkes entgegenstellt [werden], durch welches es für absehbare Zeit gebunden und majorisiert wird ${ }^{86}$. Offenkundig greift Werfel geopolitischen Gedanken aus diversen mitteleuropapolitischen Konzepten des 19. Jahrhunderts auf, in denen der Habsburgermonarchie die Rolle eines wichtigen politischen Gleichgewichts zugestanden wurde. Werfels supranationale Semantik von Reich bildet ferner ein politisches Gegenmodell, mit dem ein historisch älterer, sprachlich-ethnisch hybrider Kulturraum, vor der Desintegration bewahrt werden solle.

Unter dem Eindruck des Münchner Abkommens, Österreich ist längst "angeschlossen“ worden, verteidigt Werfel die Kulturelle Einheit Böhmens und damit das letzte demokratische Bollwerk in Ostmitteleuropa gegen ein aggressiv imperial agierendes Drittes Reich. Werfel bezieht sich dabei erneut auf die habsburgischen Traditionen der ČSR, als deren integraler Teil die deutschböhmische Kultur mit ihren austropetalen Tendenzen vor 1933 fungiere ${ }^{87}$. Der deutschböhmische 'Stamm' entwickele seine kollektive Identität nur in wechselseitigem Kontakt bzw. Konflikt mit den Tschechen:

Das von der Natur als unteilbare Einheit klassisch gemeißelte Land entsendet sein Stromsystem nach dem deutschen Norden, ohne von diesem auch nur einen einzigen Flußlauf zu empfangen. Der unbestreitbar deutliche Wille der Natur setzt hier der deutschen Expansion die vernünftige Grenze. Die geographische Gestaltung beweist somit, daß dieses an Schätzen reiche Böhmen dem kargen Deutschland von seiner Fülle so manches Gut abgeben, aber von ihm nichts Gutes zurückempfangen kann ${ }^{88}$.

85. Franz Werfel, „Les deux Allemagne“, in ders., Zwischen oben und unten. Aufsätze, Aphorismen, Tagebücher, literarische Nachträge, Adolf D. Klarmann (Hg.), München, Wien, Langen Müller, 1975 [1936], S. 306-312.

86. Ebd.

87. Franz Werfel, „Die kulturelle Einheit Böhmens“, in ders., Zwischen oben und unten, S. 317-321, S. 320.

88. Franz Werfel, „Das Geschenk der Tschechen an Europa“, Zwischen oben und unten, S. $313 \mathrm{f}$. Zur Entwicklung territorialer Vorstellungen und der damit verbundenen Konstruktion 
Mit diesem topographischen Interdependenzmodell knüpft Werfel u. a. an Goethe, an Palacký und an Johannes Urzidil an ${ }^{89}$. Die böhmischen Länder bilden eine eigene Welt, die zugleich ein verkleinertes „Modell des Vielvölkerstaates Österreich ${ }^{90 “}$ und eine Art intellektuellkünstlerisches Reservoir in Mitteleuropa bilde. In Werfels europapolitischer Apologie Das Geschenk der Tschechen an Europa erfolgt gar wie bei Johannes Urzidil (1922) ein Sendungstransfer, eine translatio imperii, vom längst „,angeschlossenen Österreich“ auf die Tschechoslowakei, die als ein „Organ des Gleichgewichts ${ }^{91 “ ~ i n ~ e i n e m ~ E u r o p a ~ d e r ~ k l e i n e n ~ V o ̈ l-~}$ ker, damit an Masaryks Nová Evropa [Das neue Europa] anknüpfend, das Prinzip demokratischer Rechtsstaatlichkeit aufrechterhalte. Allerdings ist es nur noch eine Minderheit, die die Konsequenzen erkennt, die mit dem Ende der deutsch-tschechischen Symbiose verbunden sind. Die „Vergewaltigung der Tschechoslowakei ${ }^{92 “}$ ", eine „selbstmörderische deutsche Kulturkatastrophe“, führe notwendig zum Untergang der Prager Kultur und Literatur. Das Münchener Abkommen ist ein „Keulenschlag gegen die Tschechen“ und zugleich „ein Dolchstoss gegen den deutschen Geist ${ }^{93 “}$, so die umgedeutete „Dolchstoßlegende“. Ähnlich

von Raum und territorialer Zugehörigkeit als Grundlage nationaler Identifikationsmuster s. Peter Haslinger, Nation und Territorium im tschechischen politischen Diskurs 18801938 (= Veröffentlichungen des Collegium Carolinum, 117), München, Oldenbourg, 2010. Vgl. auch den Prag-Essay von Ernst Weiß aus dem Jahr 1933 (ebd., S. 207-210), ursprünglich in Klaus Manns Zeitschrift Die Sammlung (Amsterdam, Dez. 1933), in dem die Prager intellektuelle und politische Szene als Gegenentwurf zu dem „engstirnigsten Egoismus, dem ,heiligen' der Nation und ,Rasse' etwas Größeres, Freieres, Freudigeres und seiner selbst Sichereres entgegenzustellen“ habe (Weiß, ebd., S. 208).

89. Gemeint sind hier die von Johann Wolfgang von Goethe und Karl August Varnhagen von Ense verfasste Rezension: Monatsschrift des vaterländischen Museums in Böhmen (In Goethe, Berliner Ausgabe. Bd. 18: Schriften zur Literatur II, Siegfrid Seidel (Hg.), Berlin-Weimar, Aufbau, 1972, S. 432-458); von František Palacký der Brief an die Paulskirchenversammlung: Eine Stimme über Oesterreichs Anschluss an Deutschland (In Ders., Gedenkblätter. Auswahl von Denkschriften, Aufsätzen und Briefen aus den letzten 50 Jahren. Als Beitrag zur Zeitgeschichte, Prag, Tempsky, 1874, S. 148-155; von Johannes Urzidil Goethe in Böhmen (Wien, Leipzig, 1932; NA: Zürich, Stuttgart, 1962 und 1965).

90. Franz Werfel, „Die kulturelle Einheit Böhmens“ in Adolf D. Klarmann (Hg.), Zwischen oben und unten, S. 317-321, S. 320.

91. Werfel, „Die kulturelle Einheit Böhmens“, S. 314.

92. Johannes Urzidil, „Rückblick auf die tchechish-deutsche Kultursymbiose [sic]“, in Padesát let. Sborník úvah a vzpomínek na masarykovu republiku [50 Jahre. Jahrbuch der Reflektionen und Erinnerungen an die Masaryksche Republik], Toronto/Ontario, 1968, S. 149-157, hier S. 154.

93. Urzidil, „Rückblick“, S. 155. 
Werfel oder Franz Spina ${ }^{94}$ prognostiziert Urzidil eine kulturelle Desintegration und das Ende einer kulturell gesehen höchst „produktiven Konkurrenz“, war doch Prag „viel, viel mehr [...] als bloss eine nationale Hauptstadt [...], die alle Voraussetzungen dafür barg, wieder das zu werden, was sie zur Zeit Karls IV. und Rudolfs II. gewesen war: ein ideologischer Brennpunkt Europas ${ }^{95}$.“

\section{Erinnerungen aus dem Exil}

Die politische Radikalisierung, die mit dem Anschluss Österreichs und der Zerstörung der Tschechoslowakei begann, führte zu einer Neudeutung der Habsburgermonarchie. Angesichts der sich durchsetzenden destruktiven Potenzen eines rassistisch aufgeladenen, integralen Nationalismus erkannte ein resignierender Urzidil Egoismus und Hass als zentrale Motive im Zusammenleben der Völker, an denen schon „Kakanien“ gescheitert sei: „,Ich hasse, also bin ich' ist eines der leidenschaftlichsten Daseinskriterien der Völker" ${ }^{96}$ " War Urzidil bis 1938 noch ein leidenschaftlicher Verfechter der multinationalen Tschechoslowakei in austriazistischer Tradition, der bis in den Zweiten Weltkrieg hinein an der Hoffnung festhielt, man könne nach dem Krieg an die Zeit vor dem Münchener Abkommen anknüpfen, so musste auch er nach 1945 die Irreversibilität einer ethnisch wie ideologisch und machtpolitisch neu kartierten Nachkriegsordnung anerkennen. Urzidil zog sich von der tagespolitischen Publizistik teilweise zurück ${ }^{97}$ und wurde zum literarischen Nachlassverwalter einer untergegangenen austriazistischen Kultur ohne realpolitische Perspektive, in deren Zentrum der literarische Topos Prag rückte, an dessen Mythisierung Urzidil tatkräftig mitwirkte ${ }^{98}$.

94. Steffen Höhne, Ludger Udolph (Hg.), Franz Spina (1868-1938). Ein Prager Slavist zwischen Universität und politischer Öffentlichkeit Köln, Weimar, Wien, Böhlau (= Intellektuelles Prag im 19. und 20. Jahrhundert, Bd. 2), 2012.

95. Johannes Urzidil, „Rückblick“, S. 157. An diesem „Mythos’ Prag“ symptomatisch in den syntagmatischen Beziehungen Prag-Kafka bzw. dem „Mythos“ Böhmen, war Urzidil mit seinem literarisch-essayistischen Werk in den Jahren nach 1945 entscheidend mit beteiligt (Urzidil, ebd., S. 155).

96. Johannes Urzidil, Bekenntnisse eines Pedanten, Zürich, München, Artemis, 1972, S. 54.

97. Gerhard Trapp, Peter Heumos, „Antibarbaros. Johannes Urzidils publizistische Tätigkeit in Medien der tschechoslowakischen Exilregierung 1940-1945“, in Bohemia 40/2, 1999, S. 417-435, hier S. 428.

98. Urzidil reflektiert insbesondere die politisch isolierte, anti-totalitäre Position, die er und andere Prager deutsche, aber auch tschechische Intellektuelle als Kulturmittler 
Die austriazistisch-supranationale Perspektive und das als Gegenmodell zum desintegrativen Nationalismus konzipierte Konzept der Symbiose wird zum zentralen Deutungsmuster der Zeit vor 1938 bzw. vor $1914^{99}$. Aus dem Konflikt zwischen landespatriotischen ${ }^{100}$ und nationalen Einstellungen erwächst das Vermächtnis bzw. die Sendung des sich nun als „hinternational ${ }^{101 " ~}$ " charakterisierenden Dichters.

Urzidil, dessen Spätwerk im Exil an der markanten Ausprägung der Prager deutschen Literatur Anteil hat ${ }^{102}$, steht den Autoren des Prager Kreises neben einschlägigen Themen, insbesondere Goethe und Böhmen, und Stoffen, vor allem durch Vorstellungen von Mystik, nahe, die gleich Kafka gegen die Veralltäglichung des Lebens eingesetzt werden. Urzidils detaillierter Realismus ist geprägt von einer "pedantischen“ Vorliebe für Kleinigkeiten sowie einer für die bilingualen Prager Autoren charakteristischen Reflexion von Sprache. Ausgehend von der Grundhaltung des Erinnerns setzt sich Urzidil aus dem US-amerikanischen Exil mit der unerreichbaren Heimat als unverzichtbare Ordnungskategorie, der Verlorenen Geliebten (1956), auseinander. Im Roman überträgt Urzidil die Verlusterfahrung einmal aus dem „Lebensgefühl eines Mutterlosen ${ }^{103 “}$ auf die verstorbene Mutter, variiert den Verlust-Topos aber wie im Prager Tryptychon mit der verlorenen Heimat Prag als handelnde Figur. „Dem Knabenlosen und späteren Mann war es bestimmt,

einnahmen: „Ich glaube fast, wir deutschen Dichter und Schriftsteller im alten Prag waren die einzigen, die aufrichtig Liebe und Versöhnung zu verbreiten suchten." (Urzidil, Bekenntnisse, S. 56). Vgl. hierzu die einschlägigen Beiträge in Steffen Höhne, Klaus Johann, Mirek Němec (Hg.), Johannes Urzidil (1896-1970). Ein „hinternationaler" Schriftsteller zwischen Böhmen und New York, Köln, Weimar, Wien, Böhlau (= Intellektuelles Prag im 19. und 20. Jahrhundert, Bd. 4), 2013.

99. Johannes Urzidil, „Rückblick“, S. 153.

100. S. den gleichwohl ironisch gebrochenen Bericht Weißensteins über seine Freundin Vlasta: „Im Streit der Nationen war sie unparteiisch. Sie hatte etwas vom Landespatriotismus, den es - wie ich höre - vor dem Jahre 1848 noch in Böhmen gegeben haben soll. Oft genug während des Krieges, wenn einer der vielen Siege der K. und k. Truppen gemeldet wurde, schlug sie vor: ,Komm mit mir auf den Hradschin zur nationalen Verbrüderung! Ich hatte allerdings den Verdacht, daß diese Verbrüderungen sie deshalb anzogen, weil sie oft vielfach mit einer Riesenprügelei endeten." (Johannes Urzidil, Prager Tryptichon, Zürich, Fretz \& Wasmuth 1960, S. 85).

101. Urzidil, ebd., S. 13.

102. Inge Fiala-Fürst, „Die Prager Erzählungen im Spätwerk Johannes Urzidils. Die Heimatstadt als verlorene Geliebte", in Hartmut Binder (Hg.), Franz Kafka und die Prager deutsche Literatur. Deutungen und Wirkungen, Bonn, Kulturstiftung der Vertriebenen, 1988, S. 143-150, hier S. 144.

103. Fiala-Fürst, ebd., S. 146. 
oder er war dazu verurteilt, von anderen Städten aus nach dem Relief des alten Prags zurückzublicken ${ }^{104}$ und somit nicht nur die Aufgabe wahrzunehmen, „einen ethnisch und sprachlich heterogenen Raum mit seinen kulturellen und mentalen Spezifika zu erfassen, sondern diesen Raum mit seinem Schreiben erst zu verkörpern: „Wo ich bin, dort ist Böhmen ${ }^{105}$. " Dieses Deutungsmuster wird auf die literarischen Gestalten wie Wenzeslaus Hollar, der seine Heimat durch die ganze Welt trägt (Das Elefantenblatt, 1962), Gorki, der die innere Sicherheit einer festen Verbundenheit mit der Heimat besitzt (Das Haus Colonna, 1965) oder Stifter, der sich sein Leben lang zum Böhmerwald zurückwendet (Der Trauermantel. Eine Erzählung aus Stifters Jugend, erstmals 1945) übertragen. „Fort von Prag, das bedeutet eben aus der Welt ${ }^{106}$.“

Diese Auseinandersetzung wird zum Vermächtnis bzw. zur Sendung des sich als „hinternational ${ }^{107}$ “ charakterisierenden Dichters. Erinnerung ist in Urzidils Spätwerk auf die untergegangene habsburgische Welt orientiert. Für den Dichter resultiert daraus die Verantwortung, gegen das vom Vergessen bedrohte anzugehen, womit Erinnern zu einer „ethischen Verpflichtung" wird ${ }^{108}$. Für Urzidil lassen sich dabei zwei Funktionen der Erinnerung erkennen: „Bewahrung der Vergangenheit" und die "Auseinandersetzung mit der Schuldhaftigkeit des Einzelnen und der Gesellschaft ${ }^{109}$." In diesem Kontext lässt sich das Prager Tryptichon als eine Komposition der individuellen (onthogenetischen) und kulturellen Erinnerung verstehen. Die Predella verweise auf die Kindheitserfahrungen, die Linke (Causa Wellmer) und Rechte (Vermächtnis eines Jünglings) Tafel verweisen auf die Zeit des Studiums, das Gesprenge (Die Zauberflöte) auf Alter und Vergänglichkeit. Dichtung wird damit zum „Katalysator des Geschehens und der Erinnerung ${ }^{110}$.“

Die Rückerinnerung an Habsburgische Traditionen ist auch für Max Brods Exilwerk konstitutiv, wobei sich die Perspektive Palästina schon nach 1918 zu zeigen beginnt. In Der Sommer den man zurückwünscht. Ein Roman aus jungen Jahren (1952) erinnert Brod an das sorglose

104. Johannes Urzidil, Prager Tryptichon, S. 29.

105. Urzidil, Bekenntnisse eines Pedanten, S. 40.

106. Urzidil, Prager Tryptichon, S. 145.

107. Urzidil, ebd., S. 13.

108. Anja Bischof, Funktion und Bedeutung von Erinnerung im erzählerischen Werk Johannes Urzidils. „... ganz und gar erfunden, aber aus einer Wirklichkeit", Frankfurt/Main, Lang, 2012, S. 157.

109. Ebd., S. 159.

110. Ebd., S. 177. 
Leben einer Prager jüdischen Familie in der Sommerfrische im Ostseebad Misdroy vor 1914, wobei biographische Reminiszenzen, der Bruder Otto, der später mit seiner gesamten Familie in Auschwitz ermordet wurde, der Zeichner und Karikaturist Walter Trier in der Gestalt eines Sohnes der Familie Speyer auf eine Zeit politischer Stabilität und Sicherheit verweisen. „Wir lebten noch ganz tief im alten auswattierten Österreich drinnen, ganz tief im Frieden, der ein ewiger Frieden schien." ${ }^{111}$ Die Wahrnehmung des fremdartigen Reichs-Deutschlands, eine Werdens-Welt mit einer latent vorhandenen Gewaltbereitschaft gegenüber der österreichischen Seinswelt ${ }^{112}$, zu dem Otto und Erwin österreichischen Abstand wahrten, weist dabei sowohl auf Brods vorzionistische, austriazistische Position, als auch auf die lebensweltlichen Einstellungen der Prager deutschen Juden ${ }^{113}$. Die autobiographischen Komponenten, verbunden mit dem Wechsel von der auktorialen Erzählform zur Ich-Form, die die Phase der Kindheit und die Konflikte um die psychische kranke Mutter und den hilflosen Vater aufgreifen, knüpfen an die im Roman Stefan Rott. Das Jahr der Entscheidung (1931) behandelte Thematik an, werden aber überlagert von Reflexionen um Gottes- und Schöpfungsvorstellungen aus Diesseits und Jenseits.

Die Erinnerung an Prag vor 1914 steht auch im Zentrum des im gleichen Jahr entstandenen Romans Beinahe ein Vorzugsschüler (1952). Der Erzähler, alter Ego von Max Brod, imaginiert aus Tel Aviv die frühere Begegnung mit dem seelenverwandten Freund Vikmath, beide besuchten das Gymnasium in der Stefansgasse in der oberen Prager Neustadt, in dem sich Schüler unterschiedlicher Stände, Konfessionen und Ethnien „unbestimmter altösterreichischer Nationalität ${ }^{114 “}$ zusammenfanden. Die Erinnerung schweift über die Mitschüler, über die mal despotischen, mal antisemitischen, mal verständnisvollen Lehrer, blickt auf ihren weiteren Weg. Mit dem Sujet knüpft Brod an die habsburgische Tradition des Schulromans an, wie sie von Robert Musil (Die Verwirrungen des Zöglings Törleß), Ludwig Winder (Hugo. Tragöde eines Knaben) oder Franz Werfel (Der Abituriententag) gestaltet wurde, hier aber gemildert um die Erfahrung eines Bildungssystems, dessen Vorteile erst vor dem Hintergrund

111. Max Brod, Der Sommer den man zurückwünscht, Göttingen, Wallstein, 2014, S. 19.

112. Gassmann, Lieber Vater, Lieber Gott?, S. 93.

113. S. zu dieser Thematik auch Brods Roman Jüdinnen (1911), den er an die Welt der böhmischen Bäder, hier Teplitz, mit ihren kakanisch geprägten Konventionen und Konversationen verlegt.

114. Max Brod, Beinahe ein Vorzugsschüler, Göttingen, Wallstein, 2014, S. 283. 
totalitärer Gleichschaltung eine gerechte Würdigung erfahren konnte. Eine Erkenntnis, die sich auch auf den Topos des Völkerkerkers Habsburg bezieht: „Der alte verrufene Polizeistaat Österreich war ja im Vergleich mit dem, was wir später erlebt haben, ein ideal freies Gebilde ${ }^{115}$. "Selbst die Auswüchse der Umsturzzeit nach 1918 erscheinen im Spiegel der späteren politisch-ideologischen Zugriffe eher harmlos:

Als nach dem Ende des Ersten Weltkrieges tschechische Volksmassen in die Redaktion eindrangen, in einigen Zimmern alles kurz und klein schlugen (in jenen Flitterwochen ihrer Unabhängigkeit nach langer österreichischer "Sklaverei“", wie sie es nannten, wollten sie überhaupt kein deutsches Blatt mehr in Prag dulden, nicht einmal ein so gemäßigtes wie das Prager Tagblatt $)^{116} \ldots$

Im Prager Tagblatt. Roman einer Zeitungsredaktion erinnert Brod, der von 1924 bis 1939 als Feuilletonredakteur beim Prager Tagblatt wirkte, aus dem Exil an die tschechoslowakische Phase des Blattes, seine Romanakteure wiederum erinnern sich an die habsburgische, wobei in der Handlung der politische Destabilisierungsprozess der europäischen Nachkriegsordnung der späten 1930er Jahre ins Zentrum rückt. Damit gelingt Brod die Verschränkung aus privatem und politischem Zerfall, das Scheitern des Protagonisten korrespondiert mit der Erosion der europäischen Nachkriegsordnung durch das immer bedrohlicher auftretende Dritte Reich, die Schatten von München fallen bereits auf die Redaktion, die ihrerseits unter Druck gerät und in Fraktionen zerfallend den Geist des kommenden „Protektorats“ antizipiert. Das Resümee des demütigen Gerichtsreporters Fliegel weist somit über das Prager Tagblatt hinaus auf die Tragik der Epoche:

„War die Zerschlagung des alten Österreich nicht eine ungeheure Dummheit? Man hätte den alten Staat verbessern, nicht verbrennen sollen. Heute fehlt er uns. Die Barbarei von Ost, die Barbarei von West hat freie Hand, auf den Trümmern einer edlen völkerverbindenden Kultur." Es waren richtige AltKleinseitner Gedanken, die ich da zu hören bekam, im Schatten der alten Kaiser- und Königsburg; Grillparzer hätte sich gefreut ${ }^{117}$.

Die narrative Verschränkung von politischer und „Liebesgeschichte“ verweist auf den unaufhaltsam aufkommenden Nationalsozialismus. Armand Tischler und seine Amour fou Karly aus Karlsbad, die alles

115. Max Brod, Prager Tagblatt. Roman einer Redaktion, Göttingen, Wallstein, 2015, S. 94.

116. Ebd., S. 46.

117. Ebd., S. 277. 
andere als eine „Distanzliebe“ pflegen $^{118}$, widerlegen auf der individuellen Ebene die Möglichkeit eines friedfertigen und harmonischen Zusammenlebens, die auf der politischen eine Entsprechung in den nationalistisch aufgeladenen Konflikten findet. Aus dem israelischen Exil erscheinen dabei weniger die tschechoslowakische Republik defizitär als vielmehr eine Nachkriegsordnung, die mit der Zerstörung der Habsburgermonarchie nicht nur ein machtpolitisches Vakuum erzeugt hatte, sondern auch deren utopischen Charakter, ein friedliches konfessions-, sprach- und nationenübergreifendes Zusammenleben kleiner Völker, delegitimierte. Entsprechend verläuft im Roman der Verfall auf der individuellen parallel zur politischen Situation, die politische Katastrophe korreliert mit der individuellen ${ }^{119}$. Und angesichts der Schatten des Hitlerismus und seiner Auswirkungen auf die Redaktion ${ }^{120}$ kann auch der Verfasser nur mehr konstatieren: „Dieses alte Prag ist ja versunken ${ }^{121}$."

Brod überträgt somit rückblickend aus dem Exil Konzepte des habsburgischen bzw. Prager Kulturtransfers in ein neues Symbiose-Modell, nach dem „in Prag kaum mehr von einer rein deutschen und einer rein tschechischen Nation“ die Rede war, „sondern nur noch von Pragern [...]. Eine Verschmelzung ist eingetreten, das Blut hat sich vermischt, kulturelle und wirtschaftliche Beziehungen locken über die Grenzen ${ }^{122}$. "Tatsächlich entstand keine „hybride“ tschechoslowakische Staatsnation, allerdings kam es neben vielfältigen kulturellen Transfers ${ }^{123}$ auf der alltagskulturellen und -sprachlichen Ebene zu einer funktionalen multilingualen Sprachsituation mit den unterschiedlichsten Interferenzerscheinungen und Mehrfachidentitäten, wenn auch nicht zu einer polyglossischen, zumal sich auch in der ČSR eine sich verstärkende Akzeptanz nationaler Narrativik auf allen Seiten zeigte. Ungeachtet vielfältiger Interaktionsorte von Cafés über Periodika bis hin zu Privathäusern (Salons), die als Kommunikationsräume des kulturellen Transfers fungierten und ungeachtet intensiver wechselseitiger Rezeptions- und Wirkungsprozesse entstand eben keine supranationale habsburgische Prager Literatur und Kultur.

118. Ebd., S. 392.

119. Ebd., S. 306.

120. Ebd., S. 400.

121. Ebd., S. 423.

122. Max Brod, Der Prager Kreis, Frankfurt/Main, Suhrkamp, 1979, S. 61.

123. Koeltzsch, Geteilte Kulturen, 2012. 


\section{Fazit}

Ausgehend von der These, dass die lebensweltlichen und diskursiven Prägungen die noch in der Habsburgermonarchie sozialisierten Autoren des Prager Kreises über 1918 hinaus literarisch wie politisch beeinflussten, kann man festhalten, dass die hier vorgestellten Texte ungeachtet der jeweils individuellen Dispositionen und Erfahrungen eine literarische Auseinandersetzung mit habsburgischen Einflüssen belegen. Rückblickend und vor dem Hintergrund der Erfahrung totalitärer Herrschaft erfolgt nicht nur eine sich verstärkende Rehabilitierung und Idealisierung des heimatlichen, nach 1948 weitgehend unzugänglichen Prag, das als Erinnerungsort eine zentrale Rolle schon während der Zwischenkriegszeit und erst recht nach 1945 einnimmt, sondern auch des gesamten habsburgischen Kontextes. Wurde „der einstmals zweitgrößte Staat Europas [...] nicht nur als politische Realität [...], sondern [...] auch aus dem historischen Bewußtsein eliminiert ${ }^{124 "}$, so zeigt sich wie eingangs bei Musil ein Fortleben in der literarischen Imagination. Insofern sind wiederum auch die Autoren des Prager Kreises Teil jenes Habsburg-Mythos, der Konzepte von kultureller Hybridität und Pluralität sowie Erfahrungen von kultureller Vielfalt, von Migrations- und Akkulturationsprozessen und von interkulturellen Begegnungen und Konflikten gegen die Zumutungen nationaler Kohärenz und Einheitlichkeit zu bewahren sucht.

124. Feichtinger, Uhl, Habsburg neu denken, S. 8. 